\title{
October 28 Highlight and Commentary
}

\section{Parietoccipital band heterotopia and mosaic LIS1 mutations}

Full mutations of LIS1 cause severe, posteriorly predominant lissencephaly-pachygyria. Using denaturing high-performance liquid chromatography, Sicca et al. identified two men with parieto-occipital subcortical band heterotopia who harbored mosaic mutations of the LIS1 gene.

see page 1042

\section{Subcortical band heterotopia: Somatic mosaicism and phenotypic variability}

Commentary by Daniela T. Pilz, MD

Mosaicism is defined as the presence of more than one genetically distinct cell line in a single individual. This phenomenon results from mutations arising postfertilization either in the somatic cells (somatic mosaicism) or in the germ cells (germline mosaicism). Somatic mosaicism is now well recognized as a significant factor in the phenotypic variability of $\mathrm{X}$-linked and autosomal dominant disorders. This postzygotic alteration is often associated with a milder phenotype, asymmetric features, or "survival" of an otherwise lethal phenotype.

Mutations in the $D C X$ gene on $\mathrm{Xq22.3}$ generally lead to classical lissencephaly (LIS) in males, and subcortical band heterotopia (SBH), a milder phenotype, in females. This observation has been attributed, at least in part, to random X-inactivation, resulting in "functional mosaicism" with effectively two populations of neurons in females. Thus neurons in which the normal allele is located on the active $\mathrm{X}$ chromosome would migrate normally and form the cortex, whereas those neurons with the mutant $D C X$ allele active cannot complete migration, and form the subcortical band.
If X-inactivation produces functional genetic mosaicism in female somatic cells, it was conceivable that mosaic postzygotic mutation events in $D C X$ would also produce a mixture of normal and mutant neurons, the latter forming a subcortical band. This has been shown in both males and females with SBH, with the abnormality more severe in the anterior part of the brain.

Mutations in the LIS1 gene on 17 p13.3 are associated with classical lissencephaly in both males and females, but with the cortical malformation more severe over the posterior rather than the anterior part of the brain, compared to $\mathrm{LIS} / \mathrm{SBH}$ due to $D C X$ mutations. Therefore, it was hypothesized that posterior rather than anterior predominant SBH could be due to somatic mosaic mutations in the LIS1 gene. This has now been elegantly demonstrated in the current article by Sicca et al. The authors describe two males with posterior SBH with mosaic LIS1 mutations, identified in two tissues, lymphocytes (mesodermal derivatives) and hair roots (ectodermal derivatives), confirming that the mutations were true findings. In addition, one of the pa-

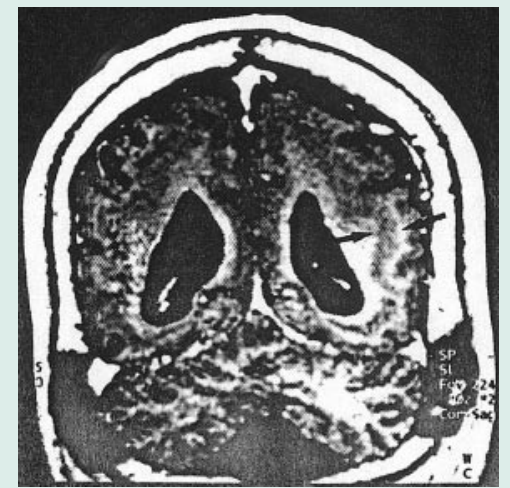

A band of heterotopic gray matter (black arrows)

tients with SBH had a mosaic nonsense mutation, which was also found as a non-mosaic mutation in another patient with more severe and generalized lissencephaly, thus demonstrating that mosaicism is a mechanism to explain milder and localized phenotypes. The technology they used, denaturing high-performance liquid chromatography, has previously shown a higher sensitivity in detecting lowlevel mosaicism than other methods. Mosaicism is emerging as an important mechanism contributing to phenotypic variability, with implications for patient care.

see page 1042 


\title{
Neurology
}

\author{
October 28 Highlight and Commentary \\ Neurology 2003;61;1027 \\ DOI 10.1212/WNL.61.8.1027
}

This information is current as of October 27, 2003

\section{Updated Information \&}

Services

Permissions \& Licensing

Reprints including high resolution figures, can be found at: http://n.neurology.org/content/61/8/1027.full

Information about reproducing this article in parts (figures,tables) or in its entirety can be found online at:

http://www.neurology.org/about/about_the_journal\#permissions

Information about ordering reprints can be found online:

http://n.neurology.org/subscribers/advertise

Neurology ${ }^{\circledR}$ is the official journal of the American Academy of Neurology. Published continuously since 1951, it is now a weekly with 48 issues per year. Copyright. All rights reserved. Print ISSN: 0028-3878. Online ISSN: 1526-632X.

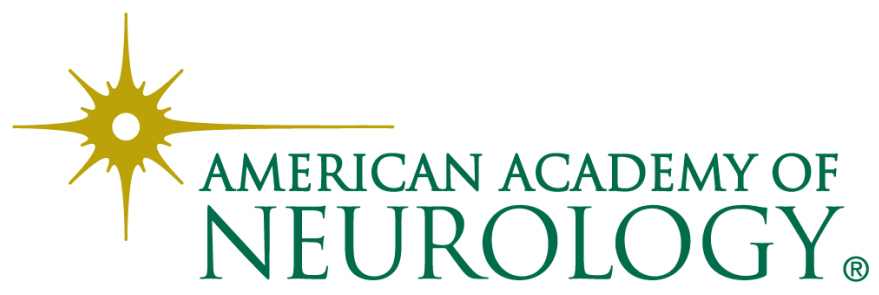

